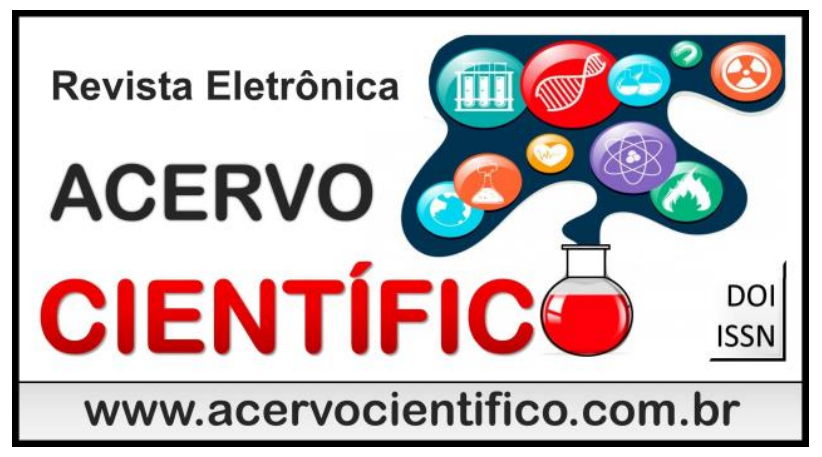

ARTIGO DE REVISÃO

Recebido em: 10/2018

Aceito em: 11/2018

Publicado em: 1/2019

\title{
O planejamento estratégico como uma vantagem competitiva de mercado: Papel do Planejador
}

\author{
Strategic planning as a competitive market advantage: Role of the Planner \\ La planificación estratégica como una ventaja competitiva de mercado: Papel del \\ planificador
}

Gleiziane Dias dos Santos $^{1 *}$, Silvana Chiaretto ${ }^{1}$

\begin{abstract}
Resumo: $O$ objeto de estudo deste artigo é a análise do papel do planejador no processo de planejamento estratégico. O principal objetivo é analisar como o perfil do planejador estratégico influência no alcance dos resultados organizacionais. Para tal fim, foi realizada uma pesquisa bibliográfica acerca do tema. Infere-se que o papel do planejador é fundamental para o alcance do sucesso de um processo de planejamento, como motivador este deve empenhar-se na busca pelos objetivos e resultados da organização de forma eficiente e eficaz.
\end{abstract}

Palavras-chave: Planejamento estratégico; Planejador; Resultado.

\begin{abstract}
This article analyzes the role of the planner in the process of strategic planning. The main goal is to analyze how the profile of the strategic planner influences in the reach of the organizational results. To that end, a literature review of the theme was carried out. It is inferred that the role of the planner is fundamental to achieving success in the planning process; as a motivator, the planner should make effort toward achieving the goals and results of the organization in an efficient and effective way.
\end{abstract}

Keywords: Strategic Planninig; Planner; Results.

Resumen: El objeto de estudio de este artículo es el análisis del papel del planificador en el proceso de planificación estratégica. El principal objetivo es analizar cómo el perfil del planificador estratégico influye en el logro de los resultados organizacionales. A tal fin, se realizó una investigación bibliográfica sobre el tema. Se observa que el papel del planificador es fundamental para el logro del éxito de un proceso de planificación, como motivador éste debe empeñarse en la búsqueda de los objetivos y resultados de la organización de forma eficiente y eficaz.

Palabras clave: Planificación estratégica; planificador; Resultado.

\footnotetext{
${ }^{1}$ Aluna do Curso de Pós-Graduação em marketing e Comunicação, Centro Universitário Uni BH, Belo Horizonte/MG. *E-mail: gleizidesantos@hotmail.com
} 


\section{INTRODUÇÃO}

A intensificação da competitividade no mercado tem levado as organizações à busca por inovação, excelência e qualificação de seus processos. O sucesso empresarial apresenta a necessidade de apresentar a conquista de resultados favoráveis em vários fatores, tais como, financeiro, cliente, desenvolvimento, etc. Neste contexto, o planejamento estratégico (PE) apresenta-se como uma ferramenta fundamental de direcionamento e organização.

O planejamento, como uma função administrativa, traz a possibilidade de estabelecimento e determinação hierarquizada de seus objetivos, direcionando a utilização de recursos e possibilitando que estes sejam aplicados de forma eficaz e eficiente.

O planejamento estratégico, como uma especificação do planejamento, é a busca pela definição precisa de objetivos, ações e atividades que devem determinar metas e a forma de alcançá-las.

Desta forma, infere-se que o Planejamento Estratégico pode proporcionar a geração de melhorias significativas na apresentação do desempenho organizacional, mas para apresentar qualidade nesses resultados é extremamente necessário o investimento voltado para a gestão, orientação e execução correta de todo o projeto do planejamento estratégico. Cabe a esta pesquisa, contextualizar a forma e possibilidade de resultados para as organizações que utilizem esta ferramenta, tendo como base a análise do papel do planejador.

Como um fator determinante para a condução e o direcionamento da empresa, é fundamental o papel do Planejador no processo de planejamento estratégico, pois o sucesso de um plano de gestão depende do acompanhamento eficaz de sua execução, sendo o resultado das metas estratégicas uma informação capaz de promover uma tomada de decisão que possa corrigir eventuais erros e fomentar direcionamentos estratégicos.

Para tanto é necessário analisar e responder ao questionamento sobre como o perfil do planejador estratégico pode influenciar no alcance dos resultados organizacionais definidos. Problemática esta que busca a possibilidade de identificar as principais características de um bom planejador e também os motivos que são determinantes para o resultado.

Nota-se grande relevância à análise desta pesquisa devida a possibilidade de apresentação e avaliação das vantagens da adoção do planejamento estratégico em uma organização e, ainda, analisar sua devida utilização e função estratégica. Assim como, a identificar a contribuição do processo para o desenvolvimento do profissional envolvido.

Ante o exposto, o estudo tem como objetivo geral analisar a importância do perfil do planejador estratégico e como este pode influenciar no alcance dos resultados organizacionais. $E$ mais especificamente: Analisar os principais conceitos de planejamento estratégico; traçar o perfil do profissional capacitado para gerir o planejamento estratégico; Decompor os principais resultados organizacionais e Relacionar o perfil do planejador estratégico com os principais resultados organizacionais.

Em uma análise hipotética, é possível entender o perfil ideal do planejador, como fundamental para todo o processo de planejamento, pois aquele que está envolvido em processos específico da organização, possuindo a capacidade de fazer os processos e áreas convergirem, identificando as necessidades da empresa e aplicando conhecimento, habilidades e tomando decisões, todos voltados para a maximização do resultado e desenvolvimento dos processos e seus colaboradores, está em um nível primordial para o desenvolvimento de todas as fases do processo;

Para tanto, optou-se, para a fundamentação da pesquisa, pela utilização da metodologia de levantamento bibliográfico, através de uma pesquisa qualitativa e descritiva, baseada na coleta de dados, com técnica de análise bibliográfica da interpretação e análise de conteúdo.

O presente trabalho está estruturado em quatro capítulos, assim organizados, sequencialmente: introdução, referencial teórico, metodologia, análise de dados e resultado. O referencial teórico apresenta quatro categorias: $O$ envolvimento do planejador nos processos da organização; Capacidades fundamentais 
do planejador para o sucesso da implementação do planejamento; Características que maximizam resultados; Resultado do planejamento como vantagem competitiva.

Por fim, este estudo buscou a resposta para o seguinte questionamento: Como o perfil do planejador estratégico influência no alcance dos resultados organizacionais?

\section{REFERENCIAL TEÓRICO}

Neste capítulo, será apresentada a análise e interpretação dos conceitos de planejamento estratégico, o perfil do profissional de $\mathrm{PE}$, resultados e a relação entre o perfil do profissional e o resultado.

\section{Conceituando planejamento Estratégico}

Para Chiavenato (2006), planejamento é o início do processo administrativo, encarregado de definir funções, estabelecer objetivos e orientar $\mathrm{o}$ alcance de resultados almejados. $\mathrm{O}$ autor nivela o planejamento em três níveis hierárquicos, a saber, estratégico, tático e operacional.

OLIVEIRA (2006, p. 34) conceitua, ainda, como:

[...] o desenvolvimento de processos, técnicas e atitudes administrativas, as quais proporcionam uma situação viável de avaliar as implicações futuras de decisões presentes em função dos objetivos empresariais que facilitarão a tomada de decisão no futuro, de modo mais rápido, coerente, eficiente e eficaz [...]

Ansoff (1990) afirma que deve haver uma identificação das oportunidades de crescimento da empresa, no qual devem ser analisados diversos aspectos que apresentem uma convergir as decisões com a busca de desempenho superior, ou seja, de vantagens competitivas.

\section{Planejamento Estratégico}

O planejamento estratégico, responsabilidade, em regra, dos níveis hierárquicos mais altos da empresa, está voltado para formulação de objetivos e também definição dos planos de ação a serem seguidos. Analisando e levando em conta os aspectos relevantes da empresa e do ambiente externo. (OLIVEIRA, 2007).

Para Chiavenato (2006, apud ALMEIDA et al, 2013), o planejamento se apresenta com cinco principais características: está relacionado a adaptação da organização a um ambiente mutável; é orientado para o futuro; é compreensivo; é um processo de construção de consenso; é uma forma de aprendizagem organizacional.

\section{Planejamento Tático}

Para Oliveira (2007), é direcionado para desenvolver-se em nível hierárquico intermediário, com objetivo principal de otimizar o uso dos recursos disponíveis no alcance dos objetivos estabelecidos.

O planejamento tático apresenta-se de forma diferente para as áreas da organização. Cada área apresentará planejamento específico para suas atividades e objetivos. Durante a construção do plano tático todos os objetivos estratégicos são desdobrados e desenvolvidos por gestores e profissionais ligados à gestão.

O planejamento tático é realizado entre dois e três anos, podendo viabilizar ações mais assertivas referindo-se ao tempo, quando comparado ao período inicial denominado nível estratégico. Logo, considerase que as ações serão executadas a médio prazo. Ele nada mais que a tradução e interpretação do nível anterior com a intenção de alcançar e realizar os objetivos propostos.

\section{Operacional}

O planejamento operacional apresenta um detalhamento do planejamento tático, mais específico é a formalização das metodologias de desenvolvimento e implantação estabelecidas anteriormente. (OLIVEIRA, 2007) 
É caracterizado por estabelecer tarefas e operações de curto prazo, objetivando apenas a realização de uma tarefa ou operação previamente definida no planejamento estratégico e determinada no planejamento tático. (GUISSONI et al, 2015).

O plano operacional executa e põe em prática os planos definidos taticamente dentro das áreas da empresa. É projetado no curto prazo e envolve cada uma das tarefas e metas da empresa.

Um planejamento operacional é o que chamamos de ações. Nele podemos descrever detalhadamente cada passo e recursos que devemos utilizar apara realizar a estratégia tática. É importante desdobrar ao máximo a estratégia, do mesmo modo que envolver profissionais operacionais. Considerando que todo a execução será feita em curto prazo o que podemos estimar em um período máximo de um ano. É a última etapa do processo de planejamento e deve assim ser mais específico e detalhado que os demais, buscando apresentar cada tarefa especificamente.

Desta maneira que os planejamentos Estratégico, Tático e Operacional trabalham juntos. Cada um tem um escopo dentro da empresa.

\section{Perfil do profissional de planejamento estratégico}

Segundo Guissoni et al (2015), uma das características do planejamento é o planejador, é o responsável pelo planejamento operacional que está inserido abaixo do nível tático. Incluindo analistas, supervisores, coordenadores. Estes são responsáveis pela coordenação das rotinas.

O autor descreve ainda as principais características de um bom planejador, quais são: Flexibilidade; Organização; Visão estratégica e operacional; Disciplina sobre o tempo; Criatividade; Proatividade; Comunicabilidade; Poder de tomar decisões; ter conhecimentos específico; etc.

O conhecimento da forma de utilização dos instrumentos de planejamento é fundamental para obtenção de bons resultados e por consequência do alcance de vantagens competitivas no mercado. É necessário o desenvolvimento e capacitação de todos os gestores e, ainda, cada uma das partes fundamentais para a execução do planejamento. Tornando-os capazes de identificar e correlacionar todos os elementos deste processo.

O planejamento estratégico permite aos gestores a percepção de todos os elementos externos (oportunidades e ameaças) e internos (pontos fortes e fracos), que servem de base para o cumprimento da missão e realizando os objetivos de forma a maximizar resultados.

\section{Resultados do Planejamento}

Todos e quaisquer Planejamentos estratégicos são meros exercícios intelectuais especulativos, se não forem colocados em prática. Administrar é, antes de tudo, obtenção de resultados. O planejamento é o meio de se chegar aos resultados planejados. (Drucker, s.d.)

Ainda segundo Drucker, o plano estratégico é apenas uma ferramenta usada com uma única finalidade, facilitar o percurso rumo aos objetivos desejados.

O sucesso de um planejamento estratégico está relacionado com o alcance de todos os resultados almejados pelo plano inicial. As decisões e ações tomadas no decorrer da execução são fundamentais e estas estão sob a responsabilidade do Planejador e todos os demais que fazem parte dos processos da empresa, tornando fundamental e necessário o envolvimento corporativo e o desenvolvimento profissional de todos, para que possam convergir com todos os planos do processo de planejamento estratégico.

\section{Relação entre os resultados e o perfil do planejador}

O perfil do planejador pode tornar-se fundamental para o resultado do planejamento estratégico, tendo em vista o nível de responsabilidade que pode ser transferida a aquele.

Para Lobato et al (2006, apud ALMEIDA et al, 2013) as funções do processo de gestão estão relacionadas, não há como ser tratado separadamente, mas sim como um sistema amplo, composto por várias funções inter-relacionada, com integração com o ambiente. O todo é considerado a soma das partes. 
Um aspecto favorável ao planejamento estratégico é a necessidade de cada Planejador, responsável por área específica e especialista na atividade que gerencia, dispor de visão global das demais áreas e das estratégias definidas e aprovadas, tornando o planejamento um exercício de interação dos conhecimentos individuais, para o bem de toda a organização. O processo de obtenção de resultados passa a depender de uma melhoria na obtenção de cada parte dos planos. (CROZATTI, s.d.)

Desta forma, o perfil do planejador ou gestor deve ser analisado com base que muitas variáveis, pois podem representar a participação de uma variedade de atores, os quais podem influenciar, não somente em suas áreas especificas de atuação, mas em todo o processo.

\title{
METODOLOGIA
}

Baseado em pesquisa bibliográfica conforme quadro 1, o desenvolvimento deste artigo foi elaborado através da análise bibliográfica, método de pesquisa escolhido, que busca em conhecimento já consolidado o embasamento para o desenvolvimento do tema escolhido.

De forma muito simples, poderíamos dizer que pesquisa é todo conjunto de ações que visa encontrar solução para um problema proposto usando processos científicos. (Marques et al, 2007).

Quadro 1 - Métodos e técnicas utilizados na pesquisa

\begin{tabular}{|c|c|c|c|}
\hline Método & Tipo de Pesquisa & $\begin{array}{c}\text { Técnicas de Coleta } \\
\text { de Dados }\end{array}$ & $\begin{array}{c}\text { Técnica de Tratamento dos } \\
\text { Dados }\end{array}$ \\
\hline $\begin{array}{c}\text { Pesquisa } \\
\text { bibliográfica }\end{array}$ & Qualitativa & $\begin{array}{c}\text { Análises } \\
\text { bibliográficas }\end{array}$ & $\begin{array}{c}\text { Interpretação e Análise de } \\
\text { conteúdo }\end{array}$ \\
\hline
\end{tabular}

Segundo Martins (2004), apresentação de diversas opiniões no momento da análise dos dados, para obtenção do desenvolvimento do problema proposto, é uma característica importante da metodologia qualitativa, quanto maior a quantidade de material, maior será a necessidade de o pesquisador apresentar capacidade integrativa e correlacionar os diversos pontos de vista.

A coleta de dados é fundamental para dar credibilidade e garantir para elaboração do estudo a fundamentação dos questionamentos apresentados. (Gil, 2010 p. 109),

De acordo com Ribeiro e Nodari (2001) a análise qualitativa pode apresentar, entre outras, a técnica de interpretação, que consiste em analisar e compreender os dados coletados de forma criteriosa e sistemática.

\begin{abstract}
ANÁLISE E RESULTADOS
O estudo foi baseado em uma pesquisa bibliográfica, pautado em teorias e análises de artigos, buscou apresentar definições do planejamento estratégico e como foco principal identificar e analisar a importância do papel do planejador na aplicação eficiente do planejamento estratégico em uma organização. Definir a forma como características e capacidades podem influenciar no resultado das metas e objetivos definidor em processos organizacionais.
\end{abstract}

Em uma análise hipotética, pode-se entender o perfil ideal do planejador como sendo aquele que está envolvido em processos específico da organização, capaz de fazer os processos e áreas convergirem, identifica as necessidades da empresa e aplica conhecimento, habilidades e toma decisões, todos voltados para a maximização do resultado e desenvolvimento dos processos e seus colaboradores. O planejador está associado a imagem de uma líder, que exercendo está liderança será capaz de conduzir a organização no alcance de metas. 


\section{Categoria 1 - 0 envolvimento do planejador nos processos da organização}

O desenvolvimento de um planejamento estratégico de excelência requer uma análise dos ambientes interno e externo. No ambiente interno, há a necessidade de uma análise detalhada dos pontos fortes e fracos, dentre esses fatores, encontra-se a necessidade de análise do perfil e capacidade dos colaboradores envolvidos.

Uma das principais características de um colaborador em uma organização está relacionada com o comprometimento. Segundo Medeiros (1997), o comprometimento está relacionado a quanto o profissional está envolvido com a organização e é identificado por três fatores, que são: a disposição em exercer um esforço necessário para o alcance de benefícios para a organização; a crença e aceitação de valores e objetivos da organização e a motivação de permanecer como membro da empresa.

Em uma análise comparativa à Teoria de Taylor, que afirma serem funções do administrador o processo de planejar, organizar, dirigir e controlar, pode-se inferir também como funções do planejador estratégico, que está inserido no mais alto escalão hierárquico da organização.

Relacionando essas funções com o processo de planejamento estratégico, exige-se do planejador que reúna diversas características e capacidades que podem influenciar no andamento e determinação dos resultados. O planejador estará presente em grande parte dos processos que envolve a aplicação do planejamento.

\section{Categoria 2 - Capacidades fundamentais do planejador para o sucesso da implementação do planejamento}

Em uma análise voltada para planejamento estratégico e propaganda, Steel (2006) enumera características e o papel de um planejador como sendo: descobrir uma solução estratégica para problemas identificados, capacidade de transformar informação em conhecimento, tornar a comunicação relevante e diferenciada, compreender e sintetizar dados, entender a organização como um todo, interpretar informações com inteligência e inovação.

Apesar de ter sua análise voltada para a área de propaganda, as características enumeradas pelo autor podem ser apresentadas, analogamente e de forma ampla, a todo o processo de planejamento estratégico, por apresentar capacidade que são exigidas e necessários para o desenvolvimento e a maximização de processos.

\section{Categoria 3 - Características que maximizam resultados}

Além de características que envolvem conhecimento e capacidades, o planejador deve apresentar e representar o papel de líder e disseminador pra ter alcance e credibilidade diante dos demais colaboradores e setores da organização.

Segundo Bohrer (s.d.), citando Maslow, a motivação ascende através de vários níveis de necessidades, as quais são: auto-realização, auto-estima, sociais, segurança e fisiológicas. A Teoria de Maslow aborda a existência de forças que impulsionam o colaborador a exercer seu papel e suas atividades.

Desta forma, cabe ao líder um papel importante como colaborador motivacional, que deve se desenvolver através de conhecimento relevante associados a boa prática da empresa, garantindo que todos os colaboradores tenham conhecimento e contato com o planejamento.

Percebe-se então a direta relação entre o perfil de líder e planejador, que em algum momento da atividade da organização podem se complementar e até mesmo se confundir. Em uma análise ampla e em sentido literal das palavras, o líder deve ser um planejador e o planejador deve ser um líder.

\section{Categoria 4 - Resultado do planejamento como vantagem competitiva}

O objetivo do planejamento é assegurar a possibilidade de atingir os objetivos e metas da organização de forma eficiente e eficaz. É fundamental para o estabelecimento dos esforços e para o alcance desses objetivos. 
Para Cyrino et al (s.d.), "o processo competitivo é caracterizado por um processo interativo de descoberta, no qual novos conhecimentos poderão ser produzidos." Tornando-se um processo cíclico, planejamento e competitividade, podendo serem vistos como complementares, pois os processos organizacionais em busca da competitividade permitem a criação de uma estratégia mais específica e voltada para feedbacks já identificado de objetivos alcançados anteriormente.

Dentre os principais objetivos das organizações, a vantagem competitiva de mercado é fundamental e é a busca destaque no ambiente mercadológico. Conforme Buttner (s.d.), a vantagem competitiva, trazida como resultado a uma organização através do planejamento estratégico poderá influenciar nos investimentos futuros.

A vantagem competitiva pode ser definida como uma apresentação de um desempenho superior no mercado, baseada em características internas da instituição.

A competição é o que mantém os processos de mercado, quando essa existe entre organizações do mesmo ramo de negócios, que procuram aumentar seus ganhos oferecendo melhor qualidade. (CYRINO et al, 2000).

Desta forma, segundo os mesmos autores, é fundamental a compreensão e a forma como os processos de mudança organizacional influenciam na interface entre a estratégia e o comportamento organizacional.

Todos os fatores que influenciam no planejamento estratégico devem estar em análise constante, para que possam manter-se atualizados e em convergências com as reais necessidades de empresa.

O insucesso na aplicação do planejamento estratégico pode ocorrer quando existem falhas no processo de implementação. (THOMPSON et al, 2003).

\section{CONSIDERAÇÕES FINAIS}

O mercado tem apresentado cada vez mais competitividade e a exigência por excelência tem se tornado algo primordial para o desenvolvimento de uma organização. Neste contexto, as empresas têm buscado ferramentas de auxílio e expansão de suas qualificações.

Embora o planejamento estratégico ainda seja incipiente em muitas organizações, ele possibilita que a empresa tenha como base fatores internos e externos que contribuem para melhor tradução do que seja o negócio e quais a suas interferências que impendem a organização de obter êxito. $O$ planejamento estratégico conduz a empresa em uma única direção, canalizando os esforços para realização dos objetivos e metas.

Desenvolvido para atender uma demanda estratégica a longo prazo, toda necessidade de atualização deve acontecer concomitante com a construção dos planos operacionais que acontecem anualmente, nos próximo três anos, após toda a consolidação do nível estratégico e aprovação do nível tático. Repetindo a cada plano operacional os mesmos objetivos estratégicos. Essas inclusões e ou alterações são primordiais para que o planejamento estratégico seja aculturado pela organização, permitindo que todos os projetos estejam contemplados em um único plano. A partir daí a ferramenta passa a ser usufruída naturalmente por todo o corpo organizacional.

O processo de planejamento estratégico apresenta a busca a melhoria e qualificação dos processos da empresa. Diante da grandeza de uma organização e dos vários colaboradores que podem estar envolvidos nos processos mencionados, há a necessidade de coordenação e direcionamento para melhoria da excelência interna e a potencialização de resultados frente à concorrência.

Para o alcance desses objetivos, a organização deve direcionar esforços e ainda centralizar algumas responsabilidades. Organização, planejamento, motivação, aceitação, são fatores fundamentais para 0 sucesso de um planejamento estratégico. 
O planejador deve, neste contexto, apresentar diversas características e capacidades, que tornem o processo de planejamento uma ferramenta que possibilite à organização buscar a maximização de resultados e o destaque no mercado, transformando as qualificações da empresa em vantagens competitivas de mercado.

As características e capacidade do planejador apresentam-se em nível de equiparação as de um líder, que são: flexibilidade; organização; visão estratégica e operacional; disciplina sobre o tempo; criatividade; proatividade; comunicabilidade; poder de tomar decisões; ter conhecimentos específicos; etc.

O líder, quando possui credibilidade diante dos liderados, consegue fazer com que haja comprometimento nos demais níveis da organização.

Para o alcance das metas e objetivos definidos no planejamento todos os colaboradores envolvidos nos processos devem estar predispostos à cooperação.

A definição de valores, visão e cultura da empresa também são fatores determinantes para seu progresso. Considera-se, então, o papel fundamental do planejador no processo de planejamento, pautando na sua importância nos diversos processos da empresa como uma totalidade e apresentado uma necessidade de aceitação, aprovação, que dependem assim de características e capacidades de um profissional qualificado.

Considera-se, ainda, a necessidade de pesquisa e análise sobre quais os fatores apresentam-se como principais desafios e objeções à atuação efetiva do planejador no processo de planejamento estratégico.

\section{REFERÊNCIAS}

1. ALMEIDA, Antônio Anderson. MENEZES, Josefa de Fátima. A importância do planejamento estratégico como fatos preponderante ao crescimento organizacional.

2. ANSOFF, H. I. Administração estratégica. São Paulo: Atlas, 1990.

3. BOHRER, Ricardo Schlatter. Motivação - abordagem crítica da teoria de Maslow pela propaganda. Online. Disponível em: http://www.scielo.br/scielo.php?pid=S0034-75901981000400004\&script=sci arttext Acesso em 26/04/2015.

4. BUTTNER, Anselmo, MORANO, Rogério Scabim. Vantagem competitiva através do Planejamento Estratégica: avaliação de firmas brasileiras de autopeças. Online. Disponível em: http://revista.feb.unesp.br/index.php/gepros/article/view/972 Acesso em 26/04/2015.

5. CHIAVENATO, Idalberto. Administração nos novos tempos. 2. ed. Rio de Janeiro: Elsevier, 2004..

6. CHIAVENATO, Idalberto. Administração estratégica. São Paulo: Saraiva, 2006

7. CYRINO, Álvaro B., VASCONCELOS. Flávio C. Vantagem competitiva: os modelos teóricos atuais e a conv ergência entre estratégia e a teoria organizacional. Online. Disponível em http://www.scielo.br/pdf/rae/v40n4/v40n4a03.pdf Acesso em 27/04/2015.

8. CROZATTI, Jaime. Planejamento estratégico e controladoria: um modelo para potencializar a contribuição das áreas da organização. Online. Dispnível em: http://www.ufrgs.br/necon/5\%20Planejamento\%20estrat\%C3\%A9gico\%20\%20Jaime\%20Crossatti.pdf Acesso em 20/04/2015

9. DRUCKER, Peter. Resultados e Planejamento. Online. Disponível: http://www.merkatus.com.br/10 boletim/259.htm Acesso em: $21 / 04 / 2015$

10. FISCHERMANN, A. A.; ALMEIDA, M.I.R. Planejamento estratégico na prática. 2. ed. São Paulo: Atlas, 1991.

11. GIL, Antônio Carlos. Como elaborar projetos de pesquisa. 5aㅡ Edição. São Paulo: Atlas, 2010.

12. GUISSONI, Leandro Angotti. Neves, Marcos Fava. Métricas para comunicação de Marketing. São Paulo: Atlas, 2015.

13. KAPLAN, R. S.; NORTON, D. P. A estratégia em ação: balanced scorecard. Rio de Janeiro: Campus, 1997.

14. MARQUES, Claudia Toffano Benevento et al. Como Elaborar Projetos de Pesquisa: Linguagem E Método. FGV Editora, 2007.

15. MARTINS, H. H. T. S. (200). Metodologia qualitativa de pesquisa. Educação e Pesquisa, 2004.

16. MAXIMIANO, Antonio César Amaru. Introdução à administração. 6.ed. São Paulo: Atlas, 2004.

17. MEDEIROS, C. A. F. Comprometimento organizacional, características pessoais e performance no trabalho: um estudo dos padrões de comprometimento organizacional. 1997.

18. OLIVEIRA, Djalma de Pinho Rebouças de. Planejamento estratégico: conceitos, metodologia e práticas. 22ª . Ed. São Paulo: Atlas, 2006.

19. OLIVEIRA, Djalma de Pinho Rebouças de. Planejamento Estratégico: conceitos, metodologia e práticas. 23a Ed. São Paulo: Atlas, 2007.

20. PORTER, M. E. Estratégia competitiva: técnicas para análise de indústrias e da concorrência. 2 ed. Rio de Janeiro: Elsevier, 2004.

21. RIBEIRO, José Luis Duarte e NODARI, Christine T. - Tratamento de dados qualitativos: técnicas e aplicações. FEENG. Porto Alegre, 2001

22. STEEL, John. A arte do planejamento: verdades, mentiras e propaganda. Rio de Janeiro: Elsevier, 2006.

23. THOMPSON, A. A.; STRICKLAND III, A. J. Planejamento estratégico: elaboração, implantação e execução. São Paulo: Pioneira Thomson Learning, 2003. 